\title{
Los pueblos y su derecho de libre determinación (a propósito del proceso independentista en Cataluña)
}

\author{
The peoples and their right of self-determination \\ (on the independence process in Catalonia) \\ Cesáreo GUTIÉRREZ ESPADA \\ Catedrático (Emérito) de Derecho Internacional Público \\ y Relaciones Internacionales \\ Universidad de Murcia \\ cgutesp@um.es
}

RECIBIDO EL 20 DE DICIEMBRE DE 2018 / ACEPTADO EL 8 DE ENERO DE 2019

Resumen: Dos son las tesis de este Estudio: una, el Derecho Internacional en vigor no avala, ni en su teoría ni en su práctica, el «derecho a decidir» que los defensores del proceso independentista alegan; y dos, este proceso es contrario a la Constitución Española en vigor. En suma, la Democracia no puede entrar en colisión con el Estado de Derecho y, menos aún, prevalecer sobre él.

Palabras clave: Derecho de libre determinación de los pueblos, secesión y Derecho Internacional, «derecho a decidir».
Abstract: Two are the theses of this Study: one, the International Law inforce not guarantee, nor in its theory nor in its practice, the «right to decide» that the defenders os de independence process allege; and two, this process is contrary to the Spanish Constitution in force. In sum, Democracy can not come into conflict with the Rule of Law and still less prevail over the same.

Keywords: Law of the peoples to self-determination, secession in International Law, «right to decide».

E

ste no es un Estudio al uso sino «la purga de mi corazón». Pero no se confunda el lector, por más que haya querido estructurarlo de la manera más simple, o más didáctica si se prefiere, en solo dos partes y una conclusión que pretenden recordar, a su vez del modo más sencillo y directo posible (como he hecho este mismo Curso con mis alumnos en clase), el Derecho Internacional en vigor, su aplicación al proceso independentista abierto en Cataluña y mi conclusión final; lo que en él podrá leerse no ha nacido del trabajo de una tarde vacía ni de un texto improvisado y escrito sin papeles. Estas líneas son el fruto de mucho tiempo de reflexión y del esfuerzo reiterado por mi parte de pasar lo que han dicho (y dicen) pero también y sobre todo de lo que han hecho (y hacen) los separatistas en Cataluña por el 
tamiz del Derecho internacional que he aprendido y he explicado en mis clases a lo largo de los años. Siempre he llegado, por lo demás, en este proceso, largo y doloroso para mí, a que esos esfuerzos me han llevado a una misma conclusión: no, ellos no tienen razón.

\section{DURA LEX ACASO PARA ALGUNOS (...)}

1. La ideología sobre la soberanía nacional que emana de las Revoluciones americana (1776) y francesa (1789), destiló el principio de las nacionalidades: toda nación, si quiere ejercer de manera efectiva su soberanía, debe convertirse en Estado. El s. XIX se convierte en una época de eclosión nacionalista, en Europa y fuera de ella:

- En Europa, porque poco a poco aparecen nuevos Estados, que rompen los vínculos que les unían con entidades más amplias: Bélgica se separa de Holanda (1831) y Grecia del Imperio Otomano (1832); la Revolución de 1848 provoca, asimismo, la creación de nuevos Estados, que «salen» también del Imperio de la Sublime Puerta (como, en 1878, Serbia, Rumania o Montenegro), consiguiendo además, desde la otra cara del espejo, la unificación de Alemania y de Italia.

- También la «Europa Americana» ve germinar igualmente en su seno las semillas aventadas en el «Continente-Patria», convirtiéndose así en Estados soberanos e independientes a lo largo del s. XIX las Repúblicas Americanas, antiguas colonias de España, Portugal o Gran Bretaña.

En 1884, se celebra en Berlín la Conferencia sobre el África Occidental, en la que participan Alemania, Austria-Hungría, Bélgica, Dinamarca, España, Estados Unidos, Francia, Gran Bretaña, Holanda, Italia, Portugal, Rusia, Suecia-Noruega y Turquía. El Acta General de la Conferencia, de 26 de febrero de 1885 , marca un hito en la época por varias razones ${ }^{1}$, destacando sobre todo sus artículos 34 y 35, en los que las Partes se comprometen a informarse recíprocamente cuando ocupen territorios en la costa del continente, así como a

1 Vid. ad ex. MüNCH, E., «Berlin West African Conference 1884-1885», en R. BERNHARDT (ed.), Encyclopedia of Public International Law, vol. I, 1992, pp. 389-391. 
mantener el libre comercio en sus posesiones africanas. Y como en ninguna de dichas disposiciones se establecía (para entender válida la ocupación de territorios) requisito alguno adicional al de su notificación, puede comprenderse que el instrumento firmado en la capital alemana se interpretase como una manifestación clave del reparto de África entre los Estados civilizados de Europa ${ }^{2}$.

2. Desde un punto de vista político y jurídico la historia de la colonización puede dividirse en tres fases ${ }^{3}$ : la primera tiene como «núcleo duro» la Conferencia de Berlín (1885) y en particular su Acta General, que supuso la «coordinación» del proceso colonial en África, es decir, el apogeo de la colonización; la segunda se abre con el Pacto de la Sociedad de Naciones (1919), punto de inflexión en el proceso con el establecimiento del régimen de mandatos, y que puede hacerse llegar hasta el texto de la Carta de Naciones Unidas (1945), porque en ésta, como en el Pacto, no se prohíben sino que se regulan las situaciones coloniales; en la tercera, estalla la revolución colonial, iniciándose la descolonización.

3. Si el principio de las nacionalidades se manifiesta (desde finales del s. XVIII) a lo largo del XIX, el de libre determinación de los pueblos aparece en el plano internacional a principios del s. XX como una idea-fuerza de alcance universal. De alcance universal, afirmo, porque el principio se predicaba de los pueblos en general.

En su Decreto sobre la Paz de 26 de octubre de 1917, el Gobierno soviético consideraba que toda nacionalidad, grande o pequeña, tiene derecho a expresar plenamente sus deseos ya de independencia ya de continuación en el seno de un Estado, «independientemente... de que... se encuentre en Europa o en lejanos países de ultramar». Y el Presidente Wilson de los Estados Unidos defendió (1918) este principio con carácter general en sus discursos (el de los Catorce y el de los Cuatro Puntos) ${ }^{4}$. Todos los pueblos, pues (coloniales o minorías integradas en los Imperios Austro-Húngaro y Otomano), tienen derecho de autodeterminación.

2 Von LiszT, F., Derecho Internacional Público, traducción al español de la $12^{\mathrm{a}}$ ed. alemana, Barcelona, G. Gili Editor, 1929, p. 36 (párrafo 4).

3 Ermacora, F., «Colonies and Colonial Regime», en R. Bernhardt (ed.), Encyclopedia of Public International Law, vol. I, 1992, pp. 662-666 (pp. 663-664).

4 Sobre las tesis de Lenin y Wilson vid. CASSESE, A., Self-determination of peoples. A reappraisal, Cambridge University Press, Cambridge, 1995, pp. 14-23. 
Pese a su formulación universal, con todo, el principio de libre determinación sólo se aplicó a algunos pueblos europeos (por ejemplo, al nacimiento del Estado serbo-croata-esloveno que, desde 1921, pasó a llamarse Yugoslavia), pero no a los pueblos coloniales. $\mathrm{Y}$ es que el sistema de mandatos previsto por el artículo 22 del Pacto de la Sociedad de Naciones (1919) para las colonias alemanas y turcas (los vencidos de la Primera Gran Guerra) siendo, sí, «una concesión a las ideas liberales» de la época ${ }^{5}$, no puede confundirse con el principio de libre determinación de los pueblos coloniales. Mediante los mandatos, todas las colonias alemanas y los territorios turcos de Siria, Palestina y Mesopotamia, se confiaron a una especie de tutela, en nombre de la Sociedad de Naciones, de ciertos Estados (mandatarios). Los mandatos se clasificaron en tres grupos ${ }^{6}$ : reconociéndose a los del tipo $A$ prácticamente la independencia con la sola condición de aceptar la ayuda del mandatario hasta la consecución de un autogobierno efectivo (antiguos territorios turcos de Mesopotamia [Irak], Palestina y la Federación de Siria y el Gran Líbano); los del tipo $B$ estaban integrados por las colonias del África Central (Camerún, Tanganika, Togo, Ruanda-Burundi); y los mandatos del tipo $C$ se localizaban en África del Sur y en numerosas islas en el Océano Pacífico. El sistema de mandatos no había previsto plazo alguno para acceder a un régimen de autogobierno, obligándose únicamente a la Potencia mandataria a cumplir con «la misión sagrada de civilización, de asegurar el bienestar y el desarrollo de estos pueblos» (art. 22).

El principio de libre determinación de los pueblos nace, y se mantiene a lo largo al menos de las seis primeras décadas del s. XX, como una idea-fuerza de naturaleza política. Una Comisión de juristas de la Sociedad de Naciones, en el caso de las islas Aaland (1920), que deseaban dejar de ser finlandesas para pasar a ser suecas, afirmó:

«Aunque el principio de libre determinación de los pueblos ocupa un lugar importante en el pensamiento político moderno, sobre todo desde la guerra mundial, conviene destacar que no figura recogido en el Pacto de la Sociedad de Naciones. Y la consagración de este principio en cierto número

5 De Yturriaga Barberán, J.A., Participación de la ONU en el proceso de descolonización, Madrid, Consejo Superior de Investigaciones Científicas, 1968, p. 10.

6 Sobre el régimen de mandatos vid. ad ex. DiENA, G., «Les mandats internationaux», Recueil des Cours de l' Académie de Droit International de La Haye/Colected Courses..., 5, 1924-IV, pp. 215-265; WRIGHT, Q., «Sovereignty of the mandates», American fournal of International Law, 17, 1923, n. ${ }^{\circ}$, pp. 691-703. 
de tratados internacionales no basta para considerarlo como una de las reglas positivas del Derecho de Gentes... El Derecho internacional positivo no reconoce, pues, a colectivos nacionales, como tales, el derecho a separarse por un simple acto de voluntad del Estado del que forman parte» 7 .

4. Aunque las Superpotencias emergentes de la Segunda Guerra Mundial (1939-1945), y miembros permanentes del Consejo de Seguridad (Estados Unidos y URSS), defienden la libre determinación pueblos (antigua colonia de Gran Bretaña, los Estados Unidos; y con una ideología rupturista respecto del tema establecido, la URSS), otros dos miembros permanentes (Reino Unido y Francia) son grandes imperios coloniales. La Carta de Naciones Unidas (1945) no reconoce el principio de libre determinación. Su artículo 1.2 (Propósitos de la Organización), es cierto, alude al fomento de las relaciones de amistad entre los Estados con base «en el respeto... de la libre determinación de los pueblos», pero este objetivo programático no es luego desarrollado. En suma, la Carta acepta el hecho colonial y regula su mantenimiento.

Así ocurre con los territorios incluidos en el régimen de administración fiduciaria (arts. 75-91), las colonias de los Estados vencidos en la Segunda Guerra Mundial (la Somalia italiana) y los mandatos del tipo B y C de la Sociedad de Naciones (la Carta preveía incorporar también a este régimen a las colonias que las Potencias metropolitanas designaran al efecto, pero ninguna lo hizo). Es cierto que la administración de los fideicomisos por la Potencia administradora se controla por Naciones Unidas mediante la exigencia de un acuerdo de dicho Estado con el Consejo de Seguridad y la vigilancia del Consejo de Administración Fiduciaria (CAF), y también que uno de los objetivos del régimen era el de «promover el adelanto político, económico, social y educativo de los habitantes de los territorios fideicomitidos, y su desarrollo progresivo hacia el autogobierno o la independencia» (art. 76.b). Pero ni se fija plazo alguno para esa independencia ni el objetivo programado desemboca en ese resultado necesariamente. En la actualidad, sabido es, el sistema de Administración Fiduciaria ha terminado, pues todos los territorios que a él se acogían han optado ya por la independencia o libre asociación con otro Estado: los últimos algunas islas del Pacífico, adminis-

7 Dictamen de 5 de septiembre de 1920, Sociedad de Naciones: Fournal Officiel, suplemento especial n. ${ }^{\circ}$, octubre 1920 , p. 5. 
tradas por Estados Unidos (1945-1986); el Consejo de Seguridad dio por terminado el fideicomiso en $1990^{8}$.

Y, desde luego, la Carta acepta claramente el hecho colonial en el caso de los territorios no autónomos (arts. 73-74), las colonias de los vencedores o de los Estados no enemigos, algunos con verdaderos imperios coloniales (como Francia o el Reino Unido), pues no establece para ellos control práctico alguno sobre la administración que del territorio llevara a cabo la metrópoli. ¿Objetivo?: el Estado responsable debe «promover en todo lo posible...el bienestar de los habitantes de estos territorios» (art. 73), estando obligado a «transmitir regularmente al Secretario General, a título informativo y dentro de los límites que la seguridad y consideraciones de orden constitucional requieran, la información estadística y de cualquier otra naturaleza técnica que verse sobre las condiciones económicas, sociales y educativas de los territorios por los cuales son responsables...» (art. 73.e). Obsérvese: no se contempla la independencia y las obligaciones de la potencia responsable se limitan a una información regular (con límites de seguridad y orden constitucional) sobre las condiciones económicas, sociales y educativas del territorio (en ningún caso políticas).

5. La ruptura con la posición contemporizadora que la Carta (1945) tenía respecto de la colonización, triunfa con la resolución 1514 (XV), de 14 de diciembre de 1960 y su Declaración sobre la concesión de la independencia a los países y pueblos coloniales. El abandono de la ambigua posición de la Carta quedó patente en su párrafo 5:

«En los territorios en fideicomiso y no autónomos y en todos los demás territorios que no han logrado su independencia deberá tomarse inmediatamente medidas para traspasar todos los poderes a los pueblos de esos territorios, sin condiciones ni reservas, en conformidad con su voluntad y sus deseos libremente expresados, y sin distinción de raza, credo ni color, para permitirles gozar de una libertad y una independencia absolutas».

Pero ¿qué es un pueblo colonial? (...). La resolución 1541 (1960) de la Asamblea General ofrece una noción útil al referirse, en cuanto territorios no autónomos, a los colectivos que habitan un territorio geográficamente separa-

8 S/RES/683 (1990), de 22 de diciembre. 
do del país que lo administra y distinto de éste étnica o culturalmente (principio IV); pero en la práctica, la identificación de un pueblo colonial depende de un órgano (no previsto en la Carta): el Comité de Descolonización o Comité de los Veinticuatro, con el mandato de vigilar el cumplimiento de la resolución 1514\%. Esta abrió un proceso en el que aparecen dos jalones:

- Uno, la resolución 1541 (XV), de 15 de diciembre de 1960, que la complementa y aclara; en la 1514 (XV), en efecto, se asimila el derecho de libre determinación con la independencia del pueblo colonial, pero solo un día después la 1541 (XV) declara que junto a la independencia hay otras formas a través de las cuales puede ejercer su derecho: la asociación y la integración en un Estado pre-existente, el metropolitano u otro (principios VII-IX), siendo lo decisivo, sea cual sea el resultado, que el pueblo colonial se manifieste libremente. Por eso, la resolución 1541 (XV) exige que la preceptiva consulta se haga mediante «procedimientos democráticos», que garanticen la expresión de la voluntad popular, y en su principio IX (sobre la integración) se precisa: procedimientos aplicados imparcialmente y con base en el sufragio universal de los adultos, pudiendo ser vigilados en su preparación, desarrollo y escrutinio mismo por Naciones Unidas.

- El otro texto relevante es la resolución 2625 (XXV), de 24 de octubre de 1970, cuya Declaración aneja incluye el principio sobre la igualdad de derechos y libre determinación de los pueblos; en él, se mantiene la lectura amplia del derecho de libre determinación, de modo que el ejercicio válido del mismo puede desembocar en el:

«establecimiento de un Estado soberano e independiente, la libre asociación o integración con un Estado independiente o la adquisición de cualquier otra condición política libremente decidida por un pueblo» (Principio de...libre determinación de los pueblos, párrafo cuarto).

Repárese, entonces, que el llamado Plan Baker para el Sahara (una autonomía importante para el pueblo saharaui integrado en Marruecos durante 5 años como paso previo a un referéndum de autodeterminación) (infra párrafo 6 in fine) sería una fórmula perfectamente válida de ser aceptada libremente por las partes, en particular por el pueblo colonial.

9 A/RES. 1654/XVI, de 27 de noviembre de 1961, de la Asamblea General. 
Otro aspecto de interés cabe destacar en la resolución 2625 (XXV), que afirma:

$\ll$ El territorio de una colonia... tiene, en virtud de la Carta de las Naciones Unidas, una condición jurídica distinta y separada de la del territorio del Estado que lo administra, y esa condición jurídica distinta y separada conforme a la Carta existirá hasta que el pueblo de la colonia... haya ejercido su derecho de libre determinación de conformidad con la Carta y, en particular, con sus propósitos y principios» (Principio de... libre determinación de los pueblos, párrafo sexto).

Con dicho pasaje, y amén de evitar la convalidación en el plano internacional de técnicas empleadas por algunas Potencias colonialistas en el pasado, como la de asimilar el territorio colonial con el metropolitano (recuérdese la «provincialización» de las antiguas colonias ultramarinas de Portugal, o las africanas de España), se siembran importantes consecuencias prácticas: así, la ilegalidad de la presencia metropolitana; o el derecho del pueblo colonial a pedir y recibir ayuda de terceros si se le niega por la fuerza su derecho de autodeterminación, sin que esta, de prestarse, infrinja el principio que prohíbe la intervención en los asuntos internos del Estado (metropolitano).

Habría que citar también los Pacto sobre derechos civiles y políticos y el relativo a los derechos económicos y sociales de Naciones Unidas (1966), en cuyo artículo 1.1 se establece que «todos los pueblos tienen derecho de libre determinación (...)»; formulación universal ésta que debidamente contextualizada aparece referida en particular a las poblaciones de los fideicomisos y territorios no autónomos y, en su caso, a la población de los Estados en general ${ }^{10}$.

6. Actualmente son escasos, pero aún existen territorios por descolonizar $^{11}$. En relación con ellos, la práctica más reciente de Naciones Unidas pone de relieve una cierta pérdida del protagonismo de la Asamblea General y del Comité de los 24 y un auge de las negociaciones directas, como sucedió en el

10 Remiro Brotons, A., «Desvertebración del Derecho internacional en la sociedad globalizada», Cursos Euromediterráneos Bancaja de Derecho Internacional, V, 2001, pp. 45-381 (p. 110); SALMón, J., «Le Droit international à l'épreuve au tournant du XXIe. Siècle», Cursos Euromediterráneos Bancaja de Derecho Internacional, VI, 2002, pp. 35-363, pp. 271-272 (parágrafo 8.4). Los Pactos de 16 de diciembre de 1966 pueden consultarse en $B O E$ de 30 de abril de 1977.

11 El listado de los «Non-Self-Governing Territorios», en http://www.un.org/en/decolonization/ nonselfgovterritories.shtml, estando la mayoría de los casos pendientes bajo soberanía británica o estadounidense [consultado: 10/12/2018]. 
caso de Nueva Caledonia, en el que el acuerdo de Numea, de 5 de mayo de 1998, entre Francia y representantes de ese territorio culminó con un estatuto de transición a la soberanía a culminar en 20 años. Otros casos presentan matices diferentes, que han obligado, incluso, al Consejo de Seguridad a actuar:

En Timor Oriental, los actos de violencia contra la población civil tras la celebración de la consulta de 30 de agosto (Acuerdo Indonesia-Portugal de 5 de mayo de 1999) y cuyo resultado fue favorable a la independencia, llevó a la adopción de la resolución 1264 (1999), de 15 de septiembre, que autorizaba la creación de una fuerza internacional para restablecer la paz. La resolución 1272 (1999), de 25 de octubre, estableció la Administración de Transición de las Naciones Unidas para Timor Oriental, que permitió su conversión en Estado en 2002.

En el Sahara Occidental, el Consejo de Seguridad aprobó la aplicación del Plan de Paz (que fijaba un periodo de transición en el que las actuaciones relativas al referéndum serían controladas por el Representante Especial del Secretario General; según el Plan, el referéndum debería haberse celebrado en 1992, pero no fue asî) y la creación de la Misión de las Naciones Unidas para el referéndum del Sahara Occidental (MINURSO) (S/RES/690/1991, de 29 de abril), pese a lo cual sigue siendo una cuestión sin resolver, por los constantes obstáculos planteados por el Reino alauita que, en 2001, se negó a aceptar (sí lo hizo el Frente Polisario) un nuevo Plan de Paz, con el patrocinio de EEUU y Francia, que preveía un régimen transitorio de autonomía para el Sahara en el seno de Marruecos, al que seguiría un referéndum sobre el estatuto definitivo del territorio.

7. El principio que consagra el derecho de libre determinación de los pueblos coloniales es hoy, sin duda, una norma consuetudinaria de carácter general, al reunir los dos elementos de la costumbre. Numerosas resoluciones de Naciones Unidas, adoptadas por unanimidad, sin votos en contra o por abrumadoras mayorías sobre casos concretos y sobre problemas o enfoques generales del tema, la práctica de los Estados con colonias (que han procedido, acatando estas resoluciones, a descolonizar sus antiguas posesiones), la incorporación de algunas de las disposiciones derivadas del derecho a la libre determinación en tratados internacionales universalmente «consentidos», todos estos hechos analizados en su conjunto permiten sustentar la existencia de una práctica general, uniforme y constante (elemento material) realizada con el convencimiento de su obligatoriedad jurídica (elemento espiritual u opinio iuris). 
Una interpretación así se ve reforzada al haber sido aceptada por la CIJ ${ }^{12}$. Más aún, nadie duda hoy que esta norma forma parte del Derecho Internacional imperativo, siendo pues de importancia fundamental para la comunidad internacional en su conjunto; la CIJ y la CDI lo han afirmado de manera inequívoca ${ }^{13}$, lo cual implica, entre otras consecuencias, que su violación grave supondrá para su autor el régimen específico que, según el Proyecto de la CDI sobre responsabilidad de los Estados, corresponde a quienes cometan ese tipo, particularmente grave, de hecho ilícitos ${ }^{14}$.

Claro que hay elementos recientes que plantean la interrogante de si el derecho de libre determinación de los pueblos coloniales no está perdiendo impulso. La resistencia de algunos Estados, «interesados» al parecer (como Estados Unidos y Francia), a que el principio no se aplique al caso del Sahara occidental del mismo modo que se había venido haciendo desde 1960 no es la única frustración; también la incongruencia de la CIJ al calificar al citado principio, en el as. de Timor Oriental (1995), de obligación erga omnes, pero sin sacar procesalmente las consecuencias pertinentes ${ }^{15}$; y otras posiblemente conectadas con las «modulaciones» a la postre introducidas en los Proyectos de artículos que la Comisión de Derecho Internacional había aprobado en relación con los crímenes contra la paz y seguridad de la humanidad y respecto

12 Opiniones consultivas de 21 de junio de 1971, as. de Namibia, CIf Recueil 1971, p. 31, párrafo 52; y de 16 de octubre de 1975, as. del Sahara occidental, CIf Recueil 1975, pp. 31-33, párrafos. 54-58.

13 Sentencia de 5 de febrero de 1970, p. 32, párrafos 33-34, asunto de la Barcelona Tractions, CIf Recueil 1970; sentencia de 30 de junio de 1995, p. 102, párrafo 29, asunto de Timor Oriental, CI7 Recueil 1995.. Por lo que a la Comisión de Derecho Internacional se refiere vid. los comentarios 4 y 5 al artículo 40 de su Proyecto de artículos sobre la responsabilidad del Estado por hechos internacionalmente ilícitos, Informe de la CDI sobre su $53^{\circ}$ período de sesiones ( 23 de abril a 1 de junio y 2 de julio a 10 de agosto de 2001). Documentos oficiales de la Asamblea General, $56^{\circ}$ período de sesiones. Suplemento $n^{o} 10$ (56/10), Nueva York, 2001, pp. 10-405 (pp. 306-307); y los comentarios al artículo 41 de su Proyecto sobre la responsabilidad de las organizaciones internacionales, Informe de la CDI sobre su $63^{\circ}$ período de sesiones (26 de abril a 3 de junio y 4 de julio a 12 de agosto de 2011). Documentos oficiales de la Asamblea General, $66^{\circ}$ período de sesiones. Suplemento $n^{\circ} 10$ (A/66/10), Nueva York, 2011, pp. 53-184 (pp. 142 ss.).

14 Para un análisis de esta cuestión vid. GUTIÉRREZ EsPaDA, C., La responsabilidad internacional (consecuencias del becho ilícito), Diego Marín Librero-Editor, Murcia, 2010, pp. 77-130; ID., La responsabilidad internacionales de las organizaciones a la luz del proyecto definitivo de artículos de la Comisión de Derecho Internacional (2011), Granada, Comares, 2012, pp. 117-125.

15 Vid. GutiérreZ Espada, C., «¿Actio popularis en Derecho Internacional?», en Drnas ZlataLerner Marcelo (ed.) y D. Zlata (coord.), Estudios de Derecho Internacional en Homenaje al Profesor Ernesto 7. Rey Caro, Martcos Lerner-Editora Córdoba, Córdoba (República Argentina), 2002, tomo I, pp. $549-575$ (pp. 568 ss.). 
de la responsabilidad del Estado por hechos internacionalmente ilícitos ${ }^{16}$ (vid. no obstante infra párrafo 10).

8. ¿Hay otros pueblos aparte de los coloniales? Sí y básicamente podrían dividirse en dos grupos: uno, hunde sus raíces en la historia (los pueblos indígenas) y otro se remite al futuro (los pueblos nacionales). No me ocuparé de los pueblos indígenas porque su problemática es más concreta y diferente de las de los otros pueblos; aunque sí recordaré que España es Parte del Convenio sobre pueblos indígenas y tribales en países independientes (Organización Internacional del Trabajo, 27 junio 1989) ${ }^{17}$; en el que se dispone un estatuto jurídico básico para colectivos de esa naturaleza, respecto de los que se reconoce sus «aspiraciones... a asumir el control de sus propias instituciones y formas de vida y de su desarrollo económico y a mantener y fortalecer sus identidades, lenguas y religiones» pero «dentro del marco de los Estados en que viven» (Preámbulo, párrafo $\left.5^{\circ}\right)^{18}$. Más desarrollo necesita el tema de los pueblos no coloniales que «viven» en un Estado soberano.

9. En síntesis, el Derecho internacional concede a los pueblos nacionales que viven en un Estado soberano derecho de libre determinación, pero con un contenido diferente al de los coloniales: a estos, el derecho les otorga (si ese fuera su deseo) la independencia, pudiendo luchar, y pedir y recibir ayuda de Estado amigos en esa lucha, si es que se les denegara el ejercicio del mismo; algunos lo sintetizan diciendo que el derecho de libre determinación asegura a los pueblos coloniales su autodeterminación externa.

El principio de libre determinación concede a los pueblos nacionales no coloniales derecho a no ser excluidos del gobierno del Estado ni ser perseguidos por su raza, credo o color; ni más ni menos; derecho, en fin, a ser tratado en

16 Vid. al respecto Remiro Brotons, A., «Desvertebración...», op. cit. (nota 10), pp. 97-101; ANDRÉS SÁENZ DE SANTAMARÍA, P., «La libre determinación de los pueblos en la nueva sociedad internacional», Cursos Euromediterráneos Bancaja de Derecho Internacional, I, 1997, pp. 113-203 (pp. 160-165).

17 Ratificado por España el 29 de enero de 2007 (BOE de 8 de marzo de 2007).

18 En relación con la actual situación de los pueblos indígenas vid. TORRECUADRADA GarCíaLozANO, S., Los pueblos indígenas en el orden internacional, Madrid, Dykinson, 2001; ID., Los derechos de los pueblos indígenas en Venezuela, Madrid, Biblioteca Nueva (Fundación Ortega y Gasset), 2010; Mariño MenÉndez, F.M. a y Oliva Martinez, J.D. (eds.): Avance en la protección de los derechos de los pueblos indígenas, Madrid, Universidad Carlos III, 2004; Oliva MARTINEZ, J.D., El Fondo para el Desarrollo de los Pueblos Indígenas de América Latina y el Caribe, La Paz (Bolivia), 2003. 
pie de igualdad, de estricta igualdad, con el resto de la población del Estado (no soy el único, la mayoría de la doctrina, con base, repárese, en la práctica, se pronuncia negativamente sobre un derecho de secesión de los pueblos no coloniales a tenor de la resolución $2625, \mathrm{XXV})^{19}$; pero intentaré ser más claro: los pueblos no coloniales tienen derecho a no ser excluidos de la gestión de la res pública del Estado, a no ser discriminados y, en definitiva, a no ser perseguidos ni oprimidos por su gobierno (vid. infra letra c de este mismo párrafo). Hay quienes lo sintetizan afirmando que los pueblos nacionales que viven en un Estado soberano tienen derecho de autodeterminación interna (no externa).

a) Acontecimientos, empero, acaecidos en Europa Central, en la que pueblos que vivieron décadas en un Estado soberano (Yugoslavia) cortaron por la fuerza de las armas sus lazos con él y son hoy Estados independientes plantearon la duda de si el Derecho internacional estaba cambiando en relación con esta norma y en su aplicación a los pueblos nacionales que forman parte de un Estado. Creo, sin embargo, que, tras la disolución de Yugoslavia, el derecho de libre determinación de los pueblos en su aplicación a los colectivos nacionales que viven en un Estado ha cambiado muy poco. Las secesiones de Eslovenia, Croacia, Bosnia y Macedonia no fueron manifestaciones prácticas del derecho de libre determinación de los pueblos. Su independencia lo fue de facto y no impulsada por la comunidad internacional ni explicable con argumentos jurídicos; esta se limitó, comprobada la irreversibilidad del proceso, a intentar fuera lo menos desestabilizador posible y procedió al reconocimiento, con condiciones varias, de los nuevos Estados ${ }^{20}$. El Derecho internacional no

19 Vid. ad ex. CASSESE, A., Self-determination. A legal reappraisal, Grotius Publications, Cambridge University Press, Cambridge, 1996 (2 ${ }^{\mathrm{a}}$ reimpresión), pp. 123-124; ANDRÉs SÁENZ DE SANTAMARÍA, P., «La libre determinación...», op. cit. (nota 16), p. 187; REMIRO BROTONS, A., «Desvertebración...», op. cit. (nota 10), pp. 110-120; KoHEN, M.G., «L'emploie de la force et la crise de Kosovo: Vers un nouveau désordre juridique international», Révue Belge de Droit International, XXXII, 1999, n. ${ }^{\circ}$ 1, pp. 122-148 (pp. 127-129); EUDES, M., «Retour sur une reussite passée inaperçue: l'Accord de Belfast et la nouvelle lectura du droit à l'autodétermination», Révue Générale de Droit International Public, 110, 2006, n. ${ }^{\circ}$ 3, pp. 630-646 (pp. 633 ss.); PÉREZ UNCETA, J.A., «El secesionismo catalán en el contexto del Derecho internacional», Foro, Nueva época (ISSN 1698-5583), vol. 17, n. ${ }^{\circ}$ 2, 2014, pp. 117-154 (p. 130). Véanse también infra las notas 25 y 30.

20 Снаршіск, E., Self-determination, terrorism and international bumanitarian law of armed conflict, M. Nijhoff, La Haya-Boston-Londres, 1996, p. 61 («In order to try to control this new area of political instability»); Antonio CASSESE entiende que el reconocimiento de las exrepúblicas yugoslavas es alentado por la Comunidad Europea sólo «cuando queda claro que el proceso de secesión es imparable», pudiendo por tanto «calificarse de proceso revolucionario que tuvo lugar más allá de las reglas de Derecho positivo vigente» (Self-determination..., op. cit., nota 19], 
ampara la secesión en el caso de los pueblos que forman parte de un Estado; aunque tampoco pueda descartarse sin más que efectividades de hecho se consoliden (solo en determinadas situaciones, que tienen que ver con la aparición de un nuevo Estado en un contexto de violación de ciertas normas imperativas, el Ordenamiento jurídico internacional prohíbe su reconocimiento).

b) La secesión de Montenegro (2006), en fin, fue pactada y prevista por el Derecho constitucional del Estado del que formaba parte: el 14 de marzo de 2002, se firma en Belgrado el Acuerdo de principios de las relaciones entre Serbia y Montenegro dentro de la Unión ${ }^{21}$; en él, Yugoslavia pasa a denominarse Serbia y Montenegro, estando conformado por ambos Estados (así calificados) y por las provincias autónomas, en el territorio serbio, de Voivodina y Kosovo; el Acuerdo, en fin, prevé la adopción de una Carta Constitucional. Uno de los aspectos esenciales del Acuerdo es su disposición sobre reconsideración, que faculta a los miembros de la Unión «a iniciar procedimientos para... la retirada del Estado unificado... una vez expirado un período de tres años» desde su entrada en vigor; se especifica en ella que si Montenegro se retira, la cuestión de Kosovo y su territorio serán competencia y permanecerán en el Estado sucesor, Serbia. En enero del 2003 se aprobó la Carta Constitucional de la Unión de Estados de Serbia y Montenegro, así como su Ley de Aplicación que en su artículo 60 recoge y precisa la disposición sobre reconsideración ${ }^{22}$. El Derecho internacional,

pp. 360, 270); y en términos análogos en esencia MARIÑO MENÉNDEZ, F.M. ${ }^{a}$, «Naciones Unidas y el derecho de autodeterminación», en MARIÑO MENÉNDEZ, F.M. ${ }^{a}$ (ed.), Balance y perspectivas de Naciones Unidas en el cincuentenario de su creación, Madrid, Universidad Carlos III de MadridBOE, 1996, pp. 77-110 (pp. 100-101); y a «respuestas coyunturales» se ha referido ANDRÉs SÁENZ DE SANTAMARÍA, P., «La libre determinación...», op. cit. (nota 16), pp. 179-182.

21 Texto en español en S/0047/02 (www.consilium.europa.eu/uedocs/cms_data/pressdata/es/ sg/69899.pdf) [consultado: 10/12/2018].

22 Dice la Carta Constitucional: «Upon the expiry of a 3-year period, member states shall have the right to initiate the proceedings for the change in its state status or for breaking away from the state union of Serbia and Montenegro. The decision on breakimg away from the State union of Serbia and Montenegro shall be taken following a referendum. The law on referendum shall be passed by a member state bearing in mind the internationally recognized democratic standrads. Should Montenegro break away from the state union of Serbia and Montenegro, the international instruments pertaining to the Federal Republic of Yugoslavia, particularly UN SC Resolution 1244, would concern and apply in their entirety to Serbia as the successor. A member state that implements this righr shall not inherit the right to international personality and all disputable issues shall be separately regulated between the successor state [adviértase que ya se ha dado su nombre, Serbia] and the newly independent state. Should both member states vote for a change in their respective state status or for independence in a referendum procedure, all disputable issues shall be regulated in a sucession procedure just as was the case with the former Socialist Federal Republic of Yuogoslavia». 
que no lo propicia, no prohíbe desde luego que los Estados concedan a sus pueblos el derecho de autodeterminación en su más amplio sentido; como en este caso ocurrió.

c) Pero sí hay en todo caso un fenómeno digno de atención y que aparece directamente relacionado con nuestra cuestión: porque Kosovo era uno de los pueblos de Yugoslavia y por él y las circunstancias que atravesaba se desencadenó una guerra que enfrentó a la OTAN con ese país. La «guerra de Kosovo» (1999) arranca de un deseo de autodeterminación del pueblo kosovar, reprimido por el Estado del que formaba parte ${ }^{23}$. En la Conferencia de Rambouillet, el plan definitivo que se oferta a Yugoslavia y a Kosovo consta de diez principios, dos son relevantes: el respeto a la integridad territorial de Yugoslavia y un alto grado de autonomía para Kosovo. Yugoslavia, finalmente, se negó a firmar el Plan de Paz. La OTAN ataca y comunica su decisión de proseguir hasta que Belgrado lo acepte. La evolución posterior de los acontecimientos confirma la presencia en toda la crisis de estos dos puntos. El Consejo de Seguridad aprobó (por 14 votos a favor y la abstención de la República Popular de China) su resolución 1244 (1999), de 10 de junio, en la que:

«en virtud del Capítulo VII de la Carta de Naciones Unidas, 1. Decide que la solución política a la crisis de Kosovo se basará en los principios generales manifestados en el anexo 1 y en los principios y condiciones más detalladas que figuran en el anexo».

En este citado Anexo 1, se reproduce la Declaración adoptada por los Ministros de AAEE del G-8, el 6 de mayo de 1999, y cuyo principio sexto exigía la apertura de un:

«proceso político dirigido al establecimiento de un acuerdo-marco político interino, que prevea para Kosovo una autonomía considerable, que tenga en cuenta los acuerdos de Rambouillet y el principio de soberanía e integridad territorial de Yugoslavia...».

La primera interrogante que surge de todo esto es: ¿obliga el Derecho internacional a Yugoslavia (para cumplir con el principio de libre determinación)

23 Vid. GutiÉRrez EsPadA, C., «Uso de la fuerza, intervención humanitaria y libre determinación (la «Guerra de Kosovo»), Anuario de Derecho Internacional, XVI, 2000, pp. 93-132 (pp. 111-112 y notas 57 y 58 de las mismas); Bermejo García, R.; Gutiérrez EsPaDA, C., La disolución de Yugoslavia, Pamplona, Eunsa, 2007, pp. 167 ss. 
a conceder a uno de sus pueblos un «amplio Estatuto de autonomía?» Muchos creíamos que, en el caso de los pueblos no coloniales (o no sometidos a una ocupación extranjera o un régimen racista), el principio mencionado sólo les daba derecho a participar en pie de igualdad en la gestión de la res publica, sin discriminación por su raza, credo o color ni persecución u opresión; y que un Estado respetuoso de este mínimo cumplía con el Derecho internacional, en virtud del párrafo $7^{\circ}$ del principio de libre determinación de los pueblos de la Declaración aneja a la resolución 2625 (XXV) de 1970 (y reproducido prácticamente por la resolución 50/6, de 24 de octubre de 1995) de la Asamblea General $^{24}$, viendo así protegida su integridad territorial por esta cláusula de salvaguardia contra eventuales secesiones.

Una interpretación de este tenor, defendida doctrinalmente, fue confirmada por el TS de Canadá en su declaración a propósito de Québec: en ésta, y citando tanto la res. 2625 (XXV) como la 50/6 en los pasajes aquí mencionados, el TS acepta que los pueblos no discriminados y que están representados sin distinción respecto de los demás que integran el Estado por el Gobierno del mismo ven respetado su derecho de autodeterminación, quedando garantizada la integridad territorial de aquél y excluyéndose, pues, un derecho unilateral a la secesión que sólo en el caso de los pueblos coloniales u oprimidos (por una ocupación militar extranjera o un régimen racista) y, acaso, los pueblos discriminados y «no representados por el Gobierno del Estado sin distinción alguna...» lo tendrían ${ }^{25}$.

24 «Ninguna de las disposiciones de los párrafos precedentes se entenderá en el sentido de que autoriza o fomenta acción alguna encaminada a quebrantar o menoscabar, total o parcialmente, la integridad territorial de los Estados soberanos e independientes que se conduzcan de conformidad con el principios de la igualdad de derechos y de la libre determinación de los pueblos antes descrito y estén por tanto, dotados de un Gobierno que represente a la totalidad del pueblo perteneciente al territorio, sin distinción por motivos de raza, credo o color» (párrafo séptimo del principio de libre determinación de la Declaración de 1970). En su párrafo 1 dedicado al tema de la $p a z$, la Declaración de 1995 reafirma el derecho de libre determinación de los pueblos y reproduce el párrafo séptimo del contenido en este principio en la Declaración de 1970, alterando sólo su parte final: «(...) de un Gobierno que represente a la totalidad del pueblo perteneciente al territorio, sin distinción alguna».

25 Supreme Court of Canada: Reference re secession of Quebec, august 20 1998, párrafos 126139 (en International Legal Materials, XXXVII, 1998, n. ${ }^{\circ}$ 6, noviembre, pp. 1.371-1.374); repárese en las dudas que el TS de Canadá tiene respecto de esta tercera excepción (la que permitiría a un pueblo cuyos derechos y libertades son cercenados por «su» Estado, el derecho a la secesión): queda, afirma, «poco claro que esta tercera propuesta refleje actualmente un estándar bien establecido de Derecho internacional» (vid. sobre todo los párrafos 135 y 138 de su declaración, International Legal Materials, op. cit., p. 1.373). Sobre esta decisión, ad ex. RoDRÍGUeZ-ZAPATA PÉREZ, J., «Autodeterminación y Constitución», Revista General de Legisla- 
Kosovo se convirtió en el gran problema pendiente de una Yugoslavia menguada y, como habremos acaso de ver, menguante hasta el final. Aunque se barajaron otras alternativas, la independencia se impuso con toda su colosal rotundidad. Tras 14 meses de negociaciones, M. Ahtisaari, Enviado Especial del Secretario General de Naciones Unidas, remitió un informe al Consejo en el que se recomendaba la independencia de Kosovo, supervisada por la comunidad internacional. El Enviado Especial justificaba su posición precisando que «Kosovo es un caso especial que requiere una solución especial [y que] no crea un precedente para otros conflictos sin resolver ${ }^{26}$. Con la Declaración de independencia de Kosovo, adoptada por su Asamblea el 17 de febrero de 2008, Serbia se enfrentó de nuevo al dilema: transigir o luchar. Dejando de lado, por realismo, toda respuesta armada se centró en denunciar la ilegalidad de la Declaración unilateral de independencia ante el Consejo de Seguridad, pero la consolidación del autoproclamado nuevo Estado va a depender en definitiva de la reacción ajena; en suma, de su reconocimiento. Estaba claro, de las circunstancias del caso, que el Consejo no prohibiría hacerlo (como en 1983, con la República Turca del Norte de Chipre), pues si alguno de sus miembros lo hubiese intentado el veto (y probablemente de más de un miembro permanente: Estados Unidos, Francia, el Reino Unido...) habría rematado la cuestión. El 18 de febrero de 2008 el Consejo de la UE, ante la imposibilidad de llegar a una posición común, dejó en libertad a los Estados miembros para decidir individualmente reconocer o no al nuevo Estado; nuestro Gobierno se negó a hacerlo, considerando ilegal la independencia proclamada.

ción y furisprudencia, III época, n. ${ }^{\circ}$ 1, enero-febrero 1999, pp. 35-58 (pp. 37-38, 43 ss.); HaJAN, D.P., «Negotiating Québec secesión», Révue Belge de Droit International, XXXI, 1998, n. ${ }^{\circ}$ 1, pp. 190-216 (pp. 198-199); BAYEFSKY, A.F., Self-determination in International Law. Québec and lessons learned, Kluwer, La Haya, 2000. Las dudas sobre el derecho a la secesión de «los pueblos (que están) en Estados independientes» se manifiestan incluso en autores que son nacionales de Estados soberanos muy jóvenes, como Croacia, que formaban parte de Yugoslavia: Así para Budislav Vukas el principio de integridad territorial de los Estados soberanos e independientes debe ser en principio respetado, admitiendo que dicho principio podrá ser ignorado en determinados supuestos solamente: «(...)si se violan los derechos humanos y libertades fundamentales, o la posición de un pueblo podría calificarse de estar bajo 'dominación extranjera', esto es bajo el dominio de otro pueblo» («States, peoples and minorities», Recueil des Cours de l'Académie de Droit International de La Haye/Collected Courses..., 231, 1991-VI, Dordrecht, 1999, pp. 263-524, en pp. 422-23).Véase también supra nota 19.

26 Informe del Enviado Especial del Secretario General sobre el estatuto futuro de Kosovo. Recomendación: el estatuto de Kosovo debe ser la independencia, supervisada por la comunidad internacional, S/2007/168, 26 marzo 2007, párrafo 15. 
No tengo nada claro que el reconocimiento del autoproclamado Estado sea conforme a Derecho (vid. infra nota 31). Es probable que la práctica, nacida en el seno de Naciones Unidas, haya traspasado sus fronteras iniciales y pueda pensarse hoy en la existencia de una norma de Derecho internacional general que obligue al no reconocimiento como Estado de entidades nacidas en violación de normas fundamentales del Derecho internacional ${ }^{27}$. Es más que posible, sí, que el Derecho internacional considere que el no reconocimiento de las situaciones creadas por la violación grave de una norma imperativa, así como no asistir ni ayudar a que se consoliden, sea una de las consecuencias de los hechos ilícitos de esta naturaleza que ya cuenta con apoyo en la práctica internacional y en las decisiones de la CIJ (as. de Namibia, 1971 o en el as. sobre las consecuencias jurídicas de la edificación de un muro en territorio palestino ocupado, 2004), contribuyendo de este modo a generalizar la práctica de Naciones Unidas del no reconocimiento colectivo. Si la ONU acabara aceptando la independencia de Kosovo, habrá arrojado al mar las cenizas de la frase de uno de sus más conocidos Secretarios Generales, el tailandés U-Thant:

«la ONU no ha aceptado nunca, no acepta y pienso que no aceptará jamás el principio de secesión de una parte de uno de sus Estados miembros» ${ }^{28}$.

La esperanza de que la CIJ, al responder a la cuestión que en tal sentido se le planteó, a iniciativa serbia, la Asamblea General de Naciones Unidas (resolución 63/3, 8 de octubre de 2008), aclarase los dos puntos claves del tema (si un pueblo que forma parte, aun estando administrado internacionalmente, de un Estado soberano puede separarse del mismo unilateralmente; y si en tales casos es conforme a Derecho el reconocimiento de la entidad secesionista), se ha desvanecido. En su opinión consultiva de 22 de julio de 2010 la CIJ (por 10 votos c. 4) se limita a decir:

«la Declaración de independencia de Kosovo adoptada el 17 de febrero de 2008 no ha violado el Derecho internacional».

La Corte, mediante una interesada, minimalista, formalista y estricta interpretación previa ad hoc de la pregunta que se le formula, elude pronunciarse

27 En este sentido, PÉREZ UNCETA, J.A., «El secesionismo catalán...», op. cit. (nota 19), p. 151.

28 «Conférence de presse du Secretaire Général», ONU. Chronique mensuelle, 7, 1970, n. ${ }^{\circ} 2$, p. 29. 
sobre las cuestiones claves a las que nos hemos referido, haciendo así, a mi juicio, un flaco favor al Derecho internacional ${ }^{29}$.

Habría sido de interés para otros casos, particularmente en relación con ese pretendido «derecho a decidir» al que aluden los gobiernos de algunos pueblos que viven en el seno de un Estado soberano que respeta su derecho de libre determinación (como Cataluña por ejemplo en España).

\section{II. (...) SED LEX}

10. Jurídicamente no existe ningún pretendido derecho a decidir, ni en el ordenamiento jurídico español ni en el ordenamiento jurídico internacional, que ampare tanto la pretensión de un referéndum o consulta como la de una declaración unilateral de independencia. No se cumplen, en el caso de Cataluña, las condiciones que el Derecho Internacional exige para que ese «derecho a decidir» fuese aplicable, esto es, que el Estado impidiese la plena participación del pueblo catalán en el gobierno del Estado, lo discriminase u oprimiese (ignorando o conculcando sus derechos y libertades fundamentales) ${ }^{30}$. Ni es

29 Gutiérrez Espada, C.; Bermejo García, R., De la Opinión consultiva de la CIf de 22 de julio de 2010 sobre Kosovo, Documento de Trabajo 35/2010, 10 de noviembre de 2010, pp. 1-13 (http:// www.realinstitutoelcano.org); Bermejo GarCÍA, R.; GutiérRez EsPADA, C., «La Declaración Unitaleral de Independencia de Kosovo a la luz de la Opinión consultiva de la CIJ, de 22 de julio de 2010 y de las declaraciones, opiniones individuales y disidentes a la misma», Anuario Español de Derecho Internacional, 26, 2010, pp. 7-59. Pueden consultarse también las colaboraciones que diversos autores han llevado a cabo en el número monográfico de la Revista Española de Derecho Internacional, LXIII, 2011, $\mathrm{n}^{\circ}$ 1, enero-junio: «La Opinión consultiva de la CIJ de 22 de julio de 2010 sobre la conformidad con el Derecho Internacional de la Declaración Unilateral de Independencia de Kosovo»; y PÉREZ UnCETA, J.A., «El secesionismo catalán...», op. cit. (nota 19), p. $152 .$.

30 En este sentido, y en aplicación concreta al proceso independentista catalán de las normas internacionales e internas españolas sobre el derecho de libre determinación de los pueblos, autores catalanes como: PONS RAFOls, X., «El denominado derecho a decidir y el Derecho internacional», en E. SEGARRA (coord.), ¿Existe el derecho a decidir? Preguntas y respuestas sobre el proceso abierto en Cataluña, Barcelona, Tibidabo, 2014, pp. 71-112 (pp. 103-104); también del mismo autor: Cataluña: derecho a decidir y Derecho Internacional, Madrid, Reus, 2015; CASANovas, O.; Rodrigo, A.P., Compendio de Derecho Internacional Público, Madrid, Tecnos, 2018

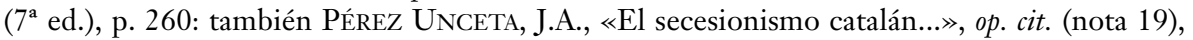
pp. 141-143. En un estudio más reciente, el profesor X. PONS RAFOLS afirma: «In my opinion International Law never protects (but also never stops protecting) these secessionist tensions (...). Only in the event of a extreme case of denial of internal self-determination (...) could an axception be made and the right to unilateral secession perhaps be justified as a remedy in International Law» («The right to political participation in International Law, independence re- 
posible, tampoco, que ese «derecho a decidir» pueda emanar sin más de la mera voluntad del pueblo en cuestión.

De particular interés en este asunto me parece la posición de Martín y Pérez de Nanclares, en ese momento Jefe de la Asesoría Jurídica Internacional del Ministerio de Asuntos Exteriores y de Cooperación (MAEC), que ha analizado con rigor las normas de la Constitución Española y el Derecho Internacional (tanto con referencia al derecho de libre determinación de los pueblos como a la legalidad del reconocimiento de los Estados nacidos de forma contraria a Derecho):

- «Inexistencia del derecho de secesión en la Constitución española de 1978: disponibilidad de mecanismos jurídicos para garantizar el adecuado cumplimiento de la Constitución».

- «Ahora bien, tal afirmación [se refiere el autor a la que defiende el derecho a decidir de Cataluña con base en el Derecho Internacional] no resulta en modo alguno sostenible en el Derecho Internacional en vigor para su aplicación a un caso como el de Cataluña»

- «Importancia práctica del reconocimiento: imposibilidad de reconocimiento en caso del nacimiento de un Estado de forma contraria a Derecho» ${ }^{31}$.

Y algo parecido podría decirse a quienes han defendido que el pueblo de Crimea (en Ucrania) tenía «derecho a decidir» salir de Ucrania para integrarse sucesivamente en Rusia ${ }^{32}$.

El Derecho Internacional, por lo demás, no prohíbe en ningún caso a que un Estado «con pueblos» decida, si es su voluntad, reconocer su derecho de secesión.

Este era el Derecho internacional en vigor aplicable al proceso independentista en Cataluña. Y lo sigue siendo. El principio de libre determinación

ferendums, and international good practice», Spanish Yearbook of International Law, 22 (2018), pp. 203-231, pp. 229-230). Estoy de acuerdo, y es también mi opinión de que en Cataluña no es aplicable esa (posible) excepción.

31 MarTín y PÉREZ DE NANClaRes, J., Reflexiones jurídicas a propósito de una eventual declaración unilateral de Cataluña: un escenario político jurídicamente inviable, pp. 7 ss., 12, 14 ss., www.realinstitutoelcano.org/www.blog.rielcano.org@rielcano, 24 de septiembre de 2015, pp. 1-37; del mismo autor puede consultarse también en inglés «Legal considerations regarding a hypothetical unilateral declaration of independence by Catalonia: a legally unfeasible political scenario», Spanish Yearbook of International Law, 19, 2015, pp. 35-59.

32 Vid. Bermejo GaRCía, R., La vuelta de Crimen a la madre-patria. Algunas reflexiones a la luz del Derecho internacional, Valencia, Tirant lo Blanch, 2015. 
de los pueblos, como lo he interpretado en las líneas precedentes sigue vivo. Me preguntaba un alumno, tras escuchar mis explicaciones en esta cuestión en una de mis clases de este mismo Curso (2018-2019), si pasados tantos años (desde la Declaración de Principios de 1970 y la Declaración de 1995 en el cincuenta aniversario de la creación de la Organización de Naciones Unidas) podríamos seguir defendiendo una categorización asi del derecho de libre determinación de los pueblos (aplicada en sentido amplio en el caso de los pueblos coloniales y en otro sentido en el de los pueblos «nacionales» que viven, boy en un Estado soberano). Y yo le respondí citando dos supuestos de la práctica internacional contemporánea:

- En 2016, Rusia y la República Popular de China firman una Declaración en cuyo párrafo 1 ambos Estados «reiteran su absoluto compromiso con los principios de derecho de internacional reflejados en (...) la Declaración de Principios de Derecho Internacional de 1970 relativos a las Relaciones de Amistad y Cooperación entre los Estados...»; y afirman que «los principios de Derecho Internacional son la piedra angular de unas relaciones internacionales justas y equitativas» ${ }^{33}$

- En 2018, el Tribunal de Justicia de la UE determinó que el Acuerdo de la UE con Marruecos sobre pesca no es aplicable al Sáhara occidental y sus aguas adyacentes porque:

«conculcaría determinadas normas de Derecho Internacional general (...) como el principio de libre determinación $\gg^{34}$.

Cuando el Gobierno español, por vez primera en su historia, aplicó el artículo 155 de la Constitución Española vigente, lo hizo (aunque posiblemente tarde y sin la contundencia que las circunstancias requerían) con base en la propia Norma Fundamental y al amparo del Derecho internacional en vigor sobre el principio de libre determinación de los pueblos. Su aplicación, por lo demás, no ha acabado con el problema. Hoy mismo, día en el que es escribo estas líneas, triunfa en todos los medios de comunicación nacionales la noticia de que el actual presidente de la Generalidad, Joaquín Torra, ha defendido

33 The Declaration of the Russian Federation and the People's Republico $f$ China on the Promotion of International Law, done at Beijing, on 25th of june, 2016 (texto en http://www.mid.ru/en_ GB/foreign_policy/news/-/asset_publisher/cKNonkJE02Bw/content/id/2331698 [consulta: $11 / 12 / 2018]$.

34 Sentencia del TJUE, asunto C-266/16, de 27 de febrero de 2018, apartado 63. 
para «el procés» la vía eslovena. ¿Recuerdan?: el uso de la fuerza, la «guerra» de secesión. Ahora sí, ahora vemos claro donde quieren (algunos) ir, más allá de la Ley, la interna y la internacional ${ }^{35}$.

$Y$ ese mismo alumno, al que me be referido supra, una vez escuchada mi respuesta, me preguntó de nuevo: y si una mayoría de catalanes deseara (no ya, comento yo, como los habitantes de las islas Aaland, en 1920, dejar de ser fineses para, por su lengua y afecto, pasar a ser suecos») convertirse en (y no formar parte de) un Estado independiente y soberano como España mismo, ¿no habría forma de respetar su deseo? Por supuesto, respondí, el Derecho internacional no impide una reforma de la Constitución Española que recogiera el «derecho a decidir» de sus Comunidades Autónomas. Si esa fuera la decisión que acabara por imponerse, el Derecho español debería, en todo caso, concretar con mucho cuidado el proceso a aplicar en tales supuestos. Hay precedentes que podría inspirar este extremo para alcanzar una regulación normativa adecuada ${ }^{36}$.

\section{CONCLUSIÓN}

Todo lo anteriormente expuesto o, dicho de otro modo, mi pensamiento se cierra en tres conclusiones. Que no voy a exponerla a continuación con mis propias palabras sino utilizando las que emplea la Declaración de los miembros (firmantes, la inmensa mayoría) de la Asociación Española de Profesores de Derecho Internacional y Relaciones Internacional (AEPDIRI) de septiembre de 2017. A saber:

$1^{a}$. Según la doctrina de las Naciones Unidas y la jurisprudencia internacional, las normas del Derecho Internacional General relativas al derecho de autodeterminación de los pueblos sólo contemplan un derecho a la inde-

35 Sobre los orígenes del conflicto en la antigua Yugoslavia y los primeros pasos que a él llevaron, los de Eslovenia (y Croacia) vid. BERMEjo GARCÍA, R.; GutiérREZ EsPADA, C., La disolución de Yugoslavia, op. cit. (nota 23), pp. 11-14, 15-83; y para un comentario actual tras las palabras del hoy presidente de la Generalitat, MoLINA, I., «La indeseable e imposible vía eslovena», 10 diciembre 2018, 08:39 h. https://elpais.com

36 Como la Canadian Clarity Act de 20 de junio de 2000 (http://www.canadianlawsite.ca/clarity-act. $\mathrm{htm}$ ) [consultado: 11/12/2018], que exige (a los referéndum pro-independencia) claridad en la pregunta y mayoría suficiente, y regula aspectos como el reparto de activos y pasivos, las fronteras o los derechos de las minorías. Sobre la «ley de claridad» véase por ejemplo CALONGE VÁzQUEZ, A., «El derecho de secesión en Canadá: una regulación jurídica completa y un problema sin resolver», Revista de Derecho de la Unión Europea, n. ${ }^{\circ}$ 25, 2013, pp. 107-124. 
pendencia en el caso de los pueblos de los territorios coloniales o sometidos a subyugación, dominación o explotación extranjeras.

A la luz de la práctica internacional, no puede excluirse un derecho de separación del Estado a comunidades territoriales cuya identidad étnica, religiosa, lingüística o cultural es perseguida reiteradamente por las instituciones centrales y sus agentes periféricos, o cuyos miembros son objeto de discriminación grave y sistemática en el ejercicio de sus derechos civiles y políticos, de forma que se produzcan violaciones generalizadas de los derechos humanos fundamentales de los individuos y de los pueblos.

Nada en los Pactos Internacionales de 1966, en ningún otro tratado sobre derechos humanos, ni en la jurisprudencia internacional apunta a la consagración de un derecho de las comunidades territoriales infraestatales a pronunciarse sobre la independencia y separación del Estado (apartados 1-3).

$2^{a}$. Cataluña no es una entidad que disfrute de un derecho de separación del Estado reconocido por el Derecho internacional (apartado 6).

$3^{\text {a }}$. Las normas generales del Derecho Internacional no prohíben que los Estados soberanos, atendiendo al principio de autoorganización, dispongan en sus propios ordenamientos jurídicos supuestos y procedimientos de separación de sus comunidades territoriales. La inmensa mayoría, lejos de hacerlo, proclaman la unidad e integridad territorial como principios básicos de su orden constitucional (apartado 4) ${ }^{37}$.

37 Declaración 19 septiembre 2017 sobre la falta de fundamentación en el Derecho Internacional del referéndum de independencia que se pretende celebrar en Cataluña (https://web6341.wixsite.com/independencia-cat) [consultado: 11/12/2018]. 